EIGHTEEN asthmatic children were challenged with ultrasonically nebulized cold distilled water (UNCDW). Blood gas composition was monitored transcutaneously (tcpO and tcpCO $\mathrm{CO}_{2}$ during and after the challenge. Assuming as basal the response to this UNCDW test, nine children (Group A) were then chosen at random to inhale cromoglycate by aerosol delivery for 8 days. Nine children (Group B), acting as a control, inhaled saline for 8 days. At the end of this therapy, each child repeated the UNCDW test. Statistical analysis with $t$-test for paired data was used to compare the results of each child to both tests. Mean basal tcpO $\mathrm{O}_{2}$ and $\operatorname{tcpCO} \mathrm{O}_{2}$ were all within the expected normal range. In all children, both mean tcpO and tcpCO $\mathrm{O}_{2}$ were reduced during and after UNCDW inhalation. Mean tcpCO values during the challenge were significantly $(p<0.001)$ lower than the corresponding steady state $2 \mathrm{~min}$ after the UNCDW challenge, with a mean drop of $-7 \%$ (2.1 S.D.). Mean tcpO, values remained significantly decreased $(p<0.001)$ from the fifth $\mathrm{min}$ of the UNCDW challenge to the end of the observation period, with a mean drop of $-20 \%$ (15.5 S.D.). After treatment with cromoglycate (Group A), the mean tcpCO values during UNCDW did not change significantly from those of steady state conditions: $-0.8 \%(0.5$ S.D.); whereas mean tcpO $\mathrm{O}_{2}$ values decreased by $-4 \%$ (4.9 S.D.). The control children treated with saline (Group B) showed mean tcpCO $\mathrm{O}_{2}$ and $\mathrm{tcpO}$, values which were significantly different $(p<0.001)$ from those of the steady state conditions: mean drop of tcpCO ${ }_{2},-6 \%$ (4.2 S.D.); mean drop of tcpO $-20 \%$ (4.7 S.D.). In conclusion, it emerges that: UNCDW induces nonspecific broncho-constriction in asthmatic children with a typical drop of tcpCO and tcpO; the treatment with cromoglycate normalizes the time course of tcpCO (hyper-reactivity) and reduces dramatically the drop of tcpO $\mathrm{O}_{2}$ time course (hyper-responsivity) during and after the UNCDW test.

Key words: Asthma, Children, Cromoglycate, $\mathrm{O}_{2}$ and $\mathrm{CO}_{2}$ time course, Ultrasonic nebulized distilled water

\section{Effect of cromoglycate on gas changes, during bronchial challenge by UNCDW in children with asthma}

\author{
L. Mappa, ${ }^{\text {CA }}$ S. Bavaro, G. Moramarco, \\ D. Torio, D. Falciatore, G. Ciccarone, \\ L. Cicciomessere and N. Rigillo
}

Istituto di Pediatria Clinica e Sociale, University of Bari Policlinico, Piazza G. Cesare, 70124 Bari, Italy

CA Corresponding Author

\section{Introduction}

Experience over the past 20 years has demonstrated the ability of cromoglycate to function as a mast cell stabilizer or inhibitor. Cromoglycate can be so considered among the anti-inflammatory drugs for asthma because it reduces bronchial hyper-reactivity ${ }^{1}$ and decreases airway hyper-responsiveness. ${ }^{2}$

This study was designed to obtain further information on the effect of cromoglycate on the time courses of transcutaneous oxygen and carbon dioxide pressure $\left(\mathrm{tcpO}_{2}\right.$ and $\mathrm{tcpCO} \mathrm{CO}_{2}$ ), during bronchial challenge by ultrasonic nebulized 'cold' distilled water (UNCDW) $)^{3,4}$ in children with asthma.

The possibility of performing continuous noninvasive monitoring of gas composition has been achieved by means of electrodes for transcutaneous $\mathrm{pO}_{2}$ and $\mathrm{pCO}_{2}$ monitoring.
This technique provides an accurate way of monitoring gas exchange changes during and after bronchial challenge. ${ }^{5}$

The bronchial challenge used is ultrasonically nebulized cold distilled water (UNCDW), which induces bronchoconstriction in children with asthma. The method is simple and reproducible, and is characterized by a high degree of specificity. ${ }^{6}$

\section{Materials and Methods}

A placebo controlled study was undertaken on 18 asthmatic children (eight males, ten females) aged 3 to 12 years, with bronchial hyper-reactivity. At the time of the investigation, all children were free of symptoms and had not received any drug during the 
previous 8 days. Before submitting children to the study, informed consent was obtained from their parents.

Transcutaneous oxygen pressure $\left(\mathrm{tcpO}_{2}\right)$ and carbon dioxide $\left.(\mathrm{tcpCO})_{2}\right)$ were monitored by the Gasthmatic system, after calibration, by placing the heated monoelectrode $\left(44^{\circ} \mathrm{C}\right)$ on the upper chest of each child and allowing a stabilization period of 15-20 min. Baseline data were collected when the $\mathrm{tcpO}_{2}$ and $\mathrm{tcpCO}$ had reached a steady state level and the children were lying quietly without body movements.

The children were then given the UNCDW test: ultrasonic nebulizer De Vilbiss Ultra-neb 99 at $5 \mathrm{ml} /$ min flow for 7 min was used. Cold distilled water was obtained by freezing it to around $0^{\circ} \mathrm{C}$, and using it just at the time of testing. The $\mathrm{tcpO}_{2}$ and $\mathrm{tcpCO}_{2}$ values were recorded in the $5 \mathrm{~min}$ before the challenge, throughout the challenge procedures, and for $30 \mathrm{~min}$ following the end of nebulization.

For statistical purposes, comparisons were made between the mean values at the steady state level before nebulization and those measured during 0-5 and $15-30 \mathrm{~min}$ after nebulization. A tcpO $\mathrm{Arop}_{2}$ of over $15 \%$ below the baseline was taken as a positive response.

Assuming the response to UNCDW test as basal, nine children (Group A) were then chosen at random to inhale cromoglycate by aerosol delivery for 8 days (20 mg three times/day). Nine children (Group B) acted as placebo control, and inhaled saline $(2 \mathrm{ml}$ three times/day) for 8 days.

At the end of this therapy, each child repeated the UNCDW test. Statistical analysis with $t$-test for paired data was used to compare the results for each child for both tests. ${ }^{7}$

\section{Results}

Basal values: The mean basal values for $\mathrm{tcpO}_{2}$ and tcpCO $\mathrm{C}_{2}$ were all within the expected normal range. There were no significant differences in these baseline variables between the two groups of subjects.

Response to UNCDW: In all children, both mean $\mathrm{tcpO}_{2}$ and $t c p \mathrm{CO}_{2}$ were reduced during and after UNCDW inhalation. $\mathrm{TcpCO}_{2}$ decreased immediately after the start of UNCDW exposure and the decrease was maximal around the third min of the challenge. The tcpCO $\mathrm{C}_{2}$ level started to pick up again immediately after the end of the exposure and the recovery was almost complete $5 \mathrm{~min}$ after the UNCDW test, with tcpCO $\mathrm{C}_{2}$ remaining more or less steady from that point onwards (Fig. 1).

The $\mathrm{tcpO}_{2}$ time course was quite different, the decrease beginning at the fourth min of UNCDW inhalation and reaching the lowest value $4 \mathrm{~min}$ after the end of exposure (Fig. 2). Mean $\mathrm{tcpCO}_{2}$ values during the challenge were significantly lower than the corresponding baseline $(p<0.001) 2$ min after the UNCDW challenge, with a mean drop of $-7 \%$ (2.1 S.D.). Mean $\mathrm{tcpO}_{2}$ values remained significantly decreased $(p<0.001)$ from the fifth min of the UNCDW challenge to the end of the observation period, with a mean drop of $-20 \%$ (15.5 S.D.).

After treatment with cromoglycate in children of Group A, the mean tcpCO $\mathrm{Calues}_{2}$ during UNCDW were not significantly different from those of steady state $\left(-0.8 \%\right.$ (0.5 S.D.)), whereas mean $\mathrm{tcpO}_{2}$ values decreased by $-4 \%$ ( 4.9 S.D.).

The children treated with saline (Group B) showed mean $\mathrm{tcpCO}_{2}$ and $\mathrm{tcpO}_{2}$ values which were significantly different $(p<0.001)$ from those of the steady state (mean drop of tcpCO $\mathrm{CO}_{2}-6 \%$ (4.2 S.D.)); mean drop of $\mathrm{tcpO}_{2}-20 \%$ (4.7 S.D.)).

Comparisons made between tcpCO $\mathrm{O}_{2} / \mathrm{O}_{2}$ data for each child of Group A to both tests (before and after therapy), showed a statistically significant difference $(p<0.001)$. Between data for each child of Group B there were no statistically significant differences to both tests.

\section{Discussion}

The possibility of monitoring blood gases with a non-invasive method (Gasthmatic) and the evalua-

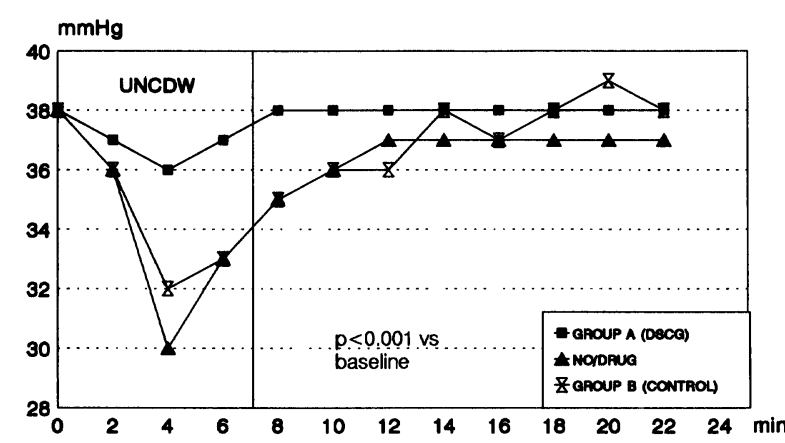

FIG. 1. Transcutaneous tcpCO time courses in asthmatic children in basal conditions (no/drug, $n=18$ ), in Group A children (DSCG, $n=9$ ) and in Group B children (control, $n=9$ ), during and after UNCDW inhalation (mean $\%$ values).

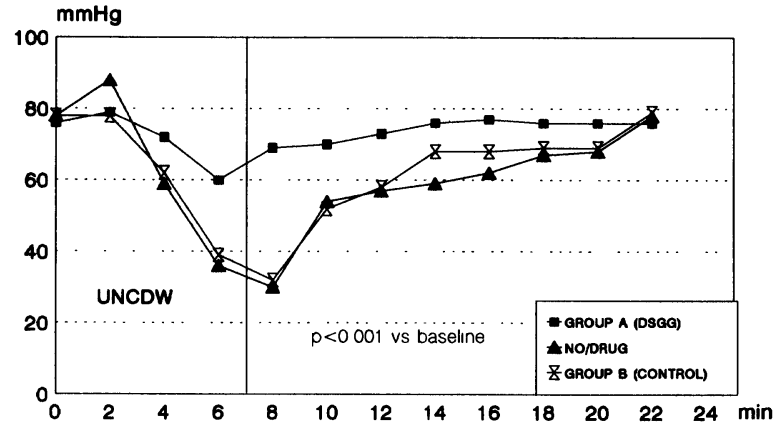

FIG. 2. Transcutaneous tcpO, time courses in asthmatic children in basal conditions (no/drug, $n=18$ ), in Group A children (DSCG, $n=9$ ) and in Group B children (control, $n=9$ ), during and after UNCDW inhalation (mean $\%$ values). 
tion in real time of their trends of variation, allowed us to identify the different bronchial structures involved in the hyper-reactive response. ${ }^{8}$

Furthermore, only in asthmatics does the bronchial challenge induce an appreciable degree of hypoxia with a later onset, shifted maximum effect, and longer duration, indicative of a mismatched ventilation/perfusion ratio.

We could verify that, unlike normal adult subjects, ${ }^{8}$ asthmatics (also free of symptoms), had unusual time courses for $\mathrm{tcpO}_{2}$ and $\mathrm{tcpCO}_{2}$ during UNCDW, namely: (1) the first phase in which tcpCO ${ }_{2}$ decreased immediately after the start of UNCDW exposure; and (2) the second phase in which $\mathrm{tcpO}_{2}$ decreased at about the fourth min of inhalation, reaching the lowest value four min after the end of exposure.

It is reasonable to suggest that the initial drop of tcpCO $\mathrm{C}_{2}$ is linked to the response of the bronchial mucosa, the first target of the challenge. This allows us to evaluate the behaviour of the bronchial epithelium which is the seat of inflammation (hyper-reactivity).

The phase following this is the contraction of the smooth muscle, leading to bronchospasm, and then to the drop in $\mathrm{tcpO}_{2}$ (hyper-responsivity).

A further demonstration of this behaviour is that the previous administration of a beta- 2 agonist drug $10 \mathrm{~min}$ before the challenge was shown to prevent the occurrence of a hypoxic response to the fog (effect on the bronchial hyper-responsivity), while the hypocapnic response remained unchanged. ${ }^{9,10}$

The treatment with anti-inflammatory drugs showed (in adults) the gradual normalization of the time courses of $\mathrm{pCO}_{2}$ (effect on bronchial hyperreactivity). ${ }^{11}$
In this study, we obtained the same time courses of blood gases during the UNCDW test in children as had been observed in adults; on the other hand, after treatment with cromoglycate (Group A), a normalization of the time course for $\mathrm{pCO}_{2}$ occurred and only a small decrease of $\mathrm{tcpO}_{2}$ (not above $10 \%$ from baseline) was observed.

In conclusion, it emerges that: UNCDW induces nonspecific bronchoconstriction in asthmatic children, with a similar time course of blood gases to that of adults; the treatment with cromoglycate normalizes the time course of $\mathrm{pCO}_{2}$ (hyper-reactivity) and reduces dramatically the drop in the $\mathrm{pO}_{2}$ time course (hyper-responsivity) during and after the UNCDW test.

\section{References}

1. Bernstein IZ. Cromolyn sodium in the treatment of asthma: coming of age in the United States. J Allergy Clin Immunol 1985; 76: 381

2. Griffin MP, MacDonald N, McFadden ER. Short- and long-term effects of cromolyn sodium on the airway reactivity of asthmatics. JAllengy Clin Immunol 1983; 71: 331.

3. Allegra L, Bianco S. Non-specific bronchoreactivity obtained with an ultrasonic aerosol of distilled water. Eur J Respir Dis 1980; 61 (Suppl 106): 41-49.

4. Mappa L, Muggeo PG, Torio D, Salerno R, Rigillo N. Bronchial challenge by ultrasonically nebulized 'cold' distilled water (UNCDW) in children with asthma. Eur Respir J Sept 1993; 6 (Suppl 17): 615s-P1980.

5. Dal Negro RW, Zoccatelli $O$, Turco $P$, Pomari $C$, Serra R. Transcutaneous $\mathrm{O}_{2}$ and $\mathrm{CO}_{2}$ monitoring in the evaluation of non-specific bronchial hyper-reactivity. SEP Newsletter No. 11. Banbury, Oxford: Cheney and Sons, 1987; 5-9.

6. Anderson SD, Schoeffel RE, Finney M. Evaluation of ultrasonically nebulized solution for provocation testing in patients with asthma. Thorax 1983; 38: 284-291. 7. Armitage P. Statistica medica. In: Metodi Statistici per la Ricerca in Medicina (5th ed.) Milan: Feltrinelli Ed: $1982 ; 188-212$.

8. Dal Negro R, Allegra L. Blood gas changes during and after nonspecific airway challenge in asthmatic and normal subject. J Appl Physiol 1989; 2627-2630.

9. Dal Negro R. Abnormal airways responses in atopy. Triangle 1988; 27: 3.

10. Turco $P$, Dal Negro R, Cogo A, Allegra L. Changes in $\mathrm{tcCO}_{2}$ time course due to ultrasonically nebulized distilled water (UNDW) in atopics before and after salbutamol. Eur Respir J 1989; 2 (Suppl): 8 (abstract).

11. Dal Negro R. La transizione tra normalità e risposta iperrattiva. Ital J Chest Dis 1989; 43 (Suppl 3): 213-218. 


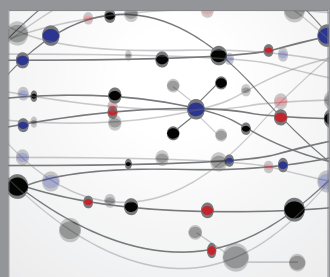

The Scientific World Journal
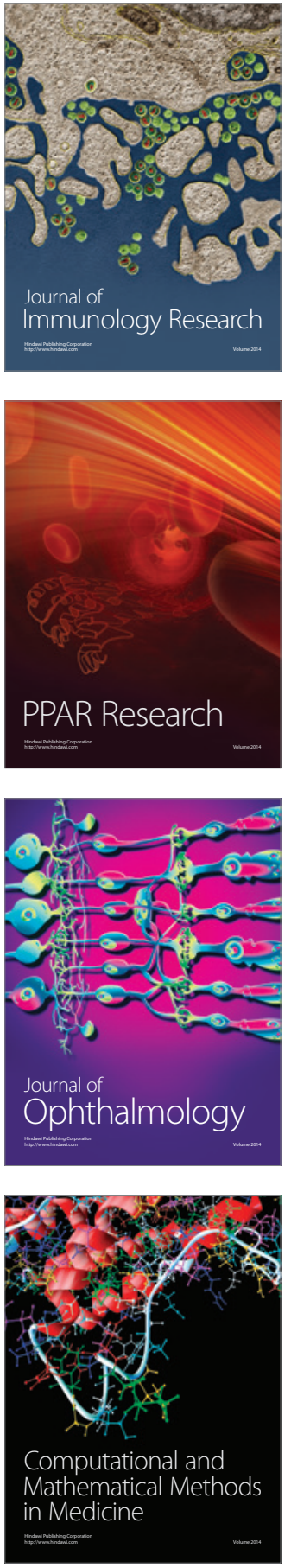

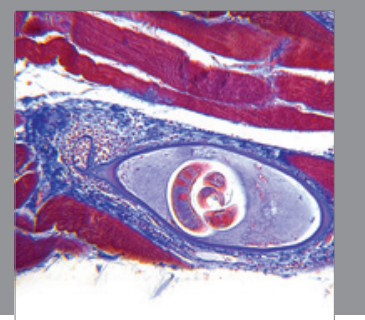

Gastroenterology

Research and Practice
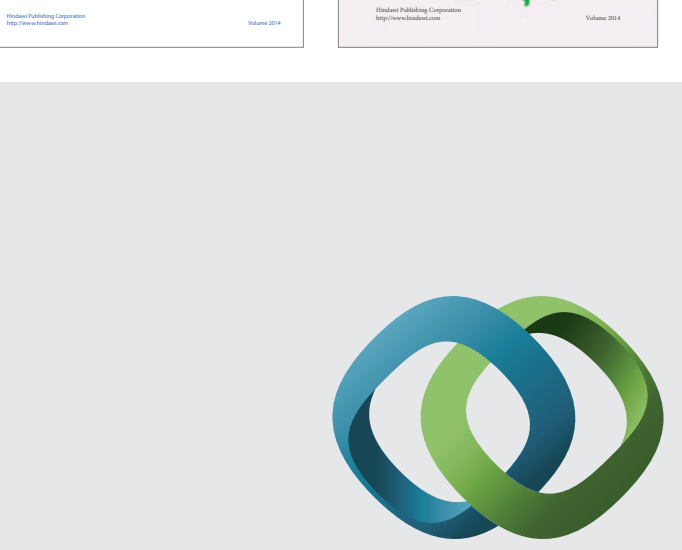

\section{Hindawi}

Submit your manuscripts at

http://www.hindawi.com
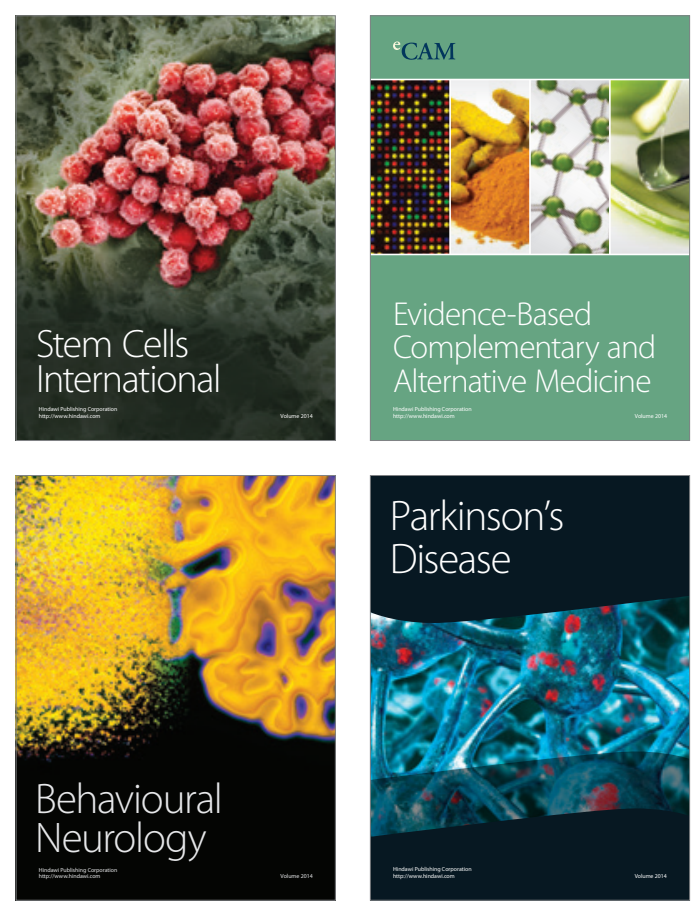

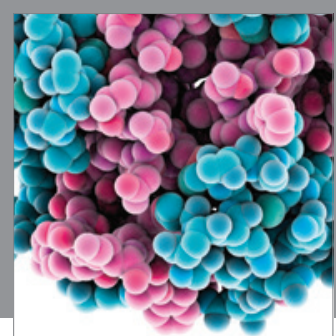

Journal of
Diabetes Research

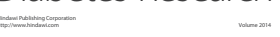

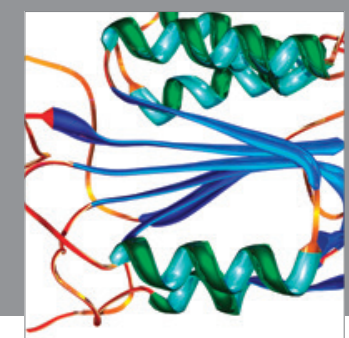

Disease Markers
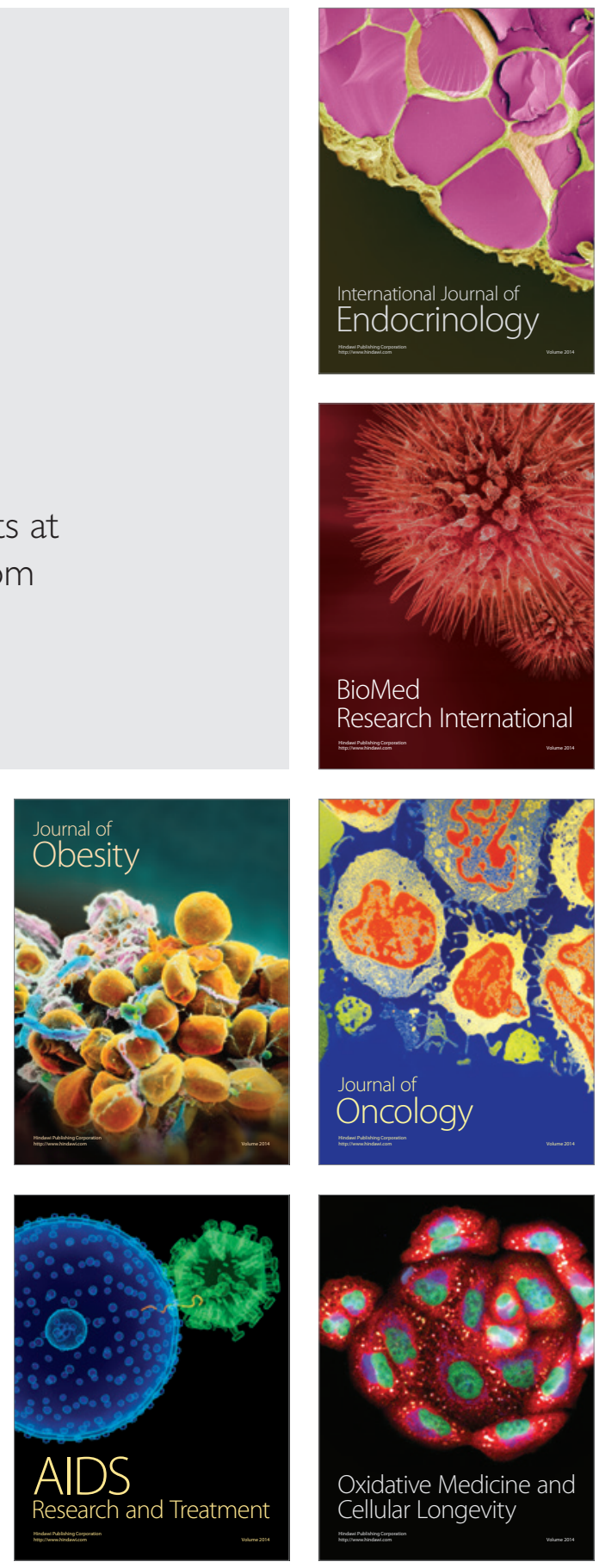